\title{
PINÓQUIO, LEITURA E ESCOLARIZAÇÃO DAS CRIANÇAS PEQUENAS: COMO TRANSFORMAM- SE EM BONECOS
}

\author{
Talula Montiel Trindade ${ }^{1}$ \\ Sandra Regina Simonis Richter ${ }^{2}$
}

INTRODUÇÃO

Ler significa aproximar-se de algo que acaba de ganhar existência. ÍTALO CALVINO, (Se um viajante numa noite de inverno)

Para enfrentar o desafio pedagógico contemporâneo posto pela entrada de bebês e crianças pequenas na Educação Básica propomos aproximar educação, literatura e infância desde a problematização da experiência de leitura nos processos iniciais de escolarização. A opção pela fenomenologia hermenêutica contribui para interrogarmos a ampla concepção escolar de leitura como experiência passível tanto de ser conduzida em seus resultados pela explicação, ou seja, de ser simplificada, "facilitada", quanto de ser administrada pelo controle do que há para ler e do tempo para ler. Ambas as atitudes apontam para o exercício escolar da vigilância do ato de ler, do controle à imaginação, em detrimento da leitura como experiência de pensamento aprendendo a pensar na alteridade, "como uma oportunidade para seguir pensando e pensar de outra maneira" (BÁRCENA, 2012, p. 92). Nossa intenção é reafirmar, com Rancière (2005, p.58), que "o real precisa ser ficcionado para ser pensado". É apenas nessa referência produtora da ficção que a experiência vital no mundo comum, em sua dimensão temporal profunda, não cessa de ser configurada e reconfigurada.

Se o debate em torno do ato de aprender a ler é recorrente no campo da educação, pois ler diz respeito à dimensão existencial do humano, Manguel (1997) e Bárcena (2004; 2012) afirmam ser a aproximação com a literatura um dos desafios educacionais mais difíceis a enfrentar hoje. O desafio está, sobretudo, em realizá-la como convite aos mais jovens aprenderem a ler o presente revitalizado pelas heranças que permitem encontrar a vida que se oculta naquela que vivemos. A lógica escolar

\footnotetext{
1 Mestranda em Educação - Universidade de Santa Cruz do Sul, UNISC. talulatrindade@gmail.com

2 Professora dos Departamentos de Educação e Pós-Graduação da Universidade de Santa Cruz do Sul - UNISC. srichter@unisc.br
} 
esquece a potência interpretativa das crianças pequenas como historicidade dos seus começos linguageiros pela desconsideração à alteridade nos seus modos de ler e interpretar, à escuta do que têm a dizer sobre si mesmas, seus modos de saber e estar em diferentes dimensões da linguagem ao constituírem suas narrativas e produzirem modos de conviver.

Estudos acerca da concepção de imaginação poética como experiência de linguagem, por nós realizados desde a interlocução entre as fenomenologias de Gaston Bachelard e Maurice MerleauPonty e a hermenêutica filosófica de Hans-Georg Gadamer, sustentam a concepção de linguagem como experiência existencial de mundo, na qual o sentido emerge quando constitui situação para o leitor, ou seja em conversação. A intenção é contribuir com outras abordagens no campo da Educação Infantil que permitam afirmar que ensinar e aprender a ler são mais, e outra coisa, que alfabetizar. Antes, diz respeito à ação de aprender a pensar, à inseparabilidade entre ler e interpretar; à potência hermenêutica do pensamento em seu inevitável pertencimento à história e à linguagem.

A partir da escuta aos ritos de iniciação de um grupo de crianças do terceiro ano do Ensino Fundamental de duas escolas estaduais do interior do Rio Grande do Sul3, na qual os alunos enviaram cartas para as crianças da pré-escola narrando como é a "realidade" da escola e como é, para ser "bom aluno", necessário sentar, ouvir, fazer fila e não atrapalhar a professora, estabelecemos um diálogo com “As Aventuras de Pinóquio", de Carlo Collodi (2011) e com "Pinóquio: um livro paralelo", uma versão de Giorgio Manganelli (2002).

O enredo ficcional da obra de Collodi contribui para a reflexão tanto em torno do imaginário escolar dos adultos e das crianças quanto em torno dos processos escolares de aprender a ler ao permitir pensar que muitas vezes esta ocupa-se mais em fabricar marionetes do que promover e favorecer condições para as crianças aprenderem a produzir sentidos e a viver outros mundos possíveis para além do que adultos acreditam ser o único, o seu. Do diálogo entre Collodi (2011) e Manganelli (2002), destacamos o paralelo entre a transformação da marionete de madeira em menino travesso nas suas (des)aventuras para fugir do controle, da escola, da obediência e a literatura como provocação, jogo, enigma e mentira na qual cada leitura é irrepetível, pois cada leitor é único. Manganelli (2002) aponta em seu "livro paralelo" que as estripulias do boneco guardam lições filosóficas - e pedagógicas - em torno da necessidade literária de suas desobediências.

Nossa expectativa ao aproximar a escuta das narrativas das crianças maiores dirigidas às pequenas em vias de iniciação escolar com a clássica história do boneco desobediente e mentiroso é

\footnotetext{
${ }^{3}$ Escuta realizada e discutida em "Como bonecos se transformam em meninos", monografia de conclusão do curso de Pedagogia da Universidade de Santa Cruz do Sul (2013).
} 
inflamar o debate em torno das concepções de leitura e literatura na educação das crianças pequenas. O desafio educacional dado pela obrigatoriedade da entrada das crianças de quatro anos na pré-escola impõe o convite ao debate em torno da experiência de ler na educação infantil. A questão que nos mobiliza é resistir à redutora concepção de literatura como leitura apenas da palavra que explica um mundo previamente definido em detrimento daquela que nos coloca no acontecimento narrado, na qual sentidos, intelecto e emoção emergem simultaneamente como experiência encarnada de linguagem que torna possível a compreensão que nos orienta nas interações, nos situa entre as coisas e no mundo pela potência lúdica das ambivalências entre real e ficcional.

\section{LEITURA ESCOLARIZADA: SIMPLIFICAR É SACRIFICAR}

La literatura nos educa en la paciência que la pedagogia ya no enseña. FERNANDO BÁRCENA (El Alma del Lector)

Desde 1996, com a Lei de Diretrizes e Bases da Educação Nacional nº 9394, é garantida a entrada de bebês e crianças pequenas na Educação Básica como dever do Estado e complementar à família, mas é a partir de 2016, pela Lei n ${ }^{\circ}$ 12.796/2013, que obrigatoriamente todas as crianças com quatro anos terão de estar matriculadas em escolas de Educação Infantil. Ao afirmar a conquista do direito social das crianças de zero a seis $\operatorname{anos}^{4}$ à educação, preconizado pela Constituição de 1988, também é afirmada maior aproximação da pré-escola ao Ensino Fundamental. Somada à matrícula obrigatória a partir dos seis anos de idade no Ensino Fundamental, em 2006, a escola passa a ocupar um espaço cada vez maior na vida das crianças pequenas, assumindo funções para além das atividades ditas curriculares. É como se a educação das crianças, antes função da família e da comunidade, mudasse de mãos e passasse por um processo de privatização. Processo este que pressupõe a ampla tendência de considerar que toda a criança seja também um aluno.

Dentre todos os conceitos de aluno, seja aquele que não tem luz ou aquele a quem se deve alimentar, a ideia que prevalece é a da criança como ser dependente, alguém em “construção". Desse modo, nos recintos escolares, a criança deve tornar-se aluno, deve ser submetida a ordens e hierarquias. Por ser literalmente um “ainda não", um aprendiz ouvinte muito mais do que um aprendiz falante, um orientado, um receptor, guiado e paciente, a criança e o aluno, destaca Narodowski (2001, p. 23), “correspondem existencialmente a um mesmo ser mas epistemologicamente constituem

\footnotetext{
${ }^{4}$ A Resolução ${ }^{\circ} 5$ do CNE/CEB, de 17 de dezembro de 2009, ao fixar as Diretrizes Curriculares Nacionais para a Educação Infantil, afirma no $\S 3^{\circ}$ do Art. $5^{\circ}$ que "As crianças que completam 6 anos após o dia 31 de março devem ser matriculadas na Educação Infantil” (BRASIL, 2009).
} 
objetos diferentes". O aluno remete à elaboração discursiva de uma infância integrada em instituições escolares, ou seja, adaptada em conteúdos curriculares, conhecimentos formais, obrigatoriedade, número mínimo de dias letivos e de horas diárias, avaliação de aprendizagens. Nesse sentido, o personagem Pinóquio ${ }^{5}$, criado por Collodi (2011) entre 1881 e 1883, encarna o imaginário de uma infância escolarizada dada pela transformação da criança em aluno.

O livro Aventuras de Pinóquio é reconhecido por assumir uma postura moralista dos adultos sobre as crianças como a do dever de serem estudiosas, obedientes e não questionadoras de seu poder, enfim, um "bom aluno". Porém, Manganelli (2002, p. 146) permite outra leitura ao escrever que "toda vez que Pinóquio fica 'obediente', estuda e é bem-comportado, não acontece mais nada". Essa ausência de acontecimentos ocorre quando finalmente o boneco começa a ir à escola. Podemos então ler e pensar com Manganelli (2002, p. 147) que "a obediência e o bom comportamento de Pinóquio são incompatíveis com a sua história, com as suas aventuras”. Mas, para além dessa constatação, Manganelli (2002), contribui para a compreensão de que, em termos literários,

a história é sempre "história de uma desobediência; pressupõe um erro, uma deserção da norma, uma condição patológica. Quanto mais se estende, subtraindo-se ao recato do vocabulário, mais a linguagem assume como suas as dimensões da doença. Não há chaga, angústia, inexistência, nada sofrido pelo ser que não se faça palavra. Para aflorar os significados cada vez mais periféricos é necessário viajar, percorrer espaços, peregrinar, fugir; é necessário se extraviar, perder o nome, dissociar-se da sociabilidade (MANGANELLI, 2002, p. 147).

Pinóquio só avança em suas desventuras, isto é, só cresce quando aprende com os conflitos e as contradições da vida. Collodi (2011) nos apresenta que crescer não é fácil, supõe enfrentar as ambiguidades entre transgressivo e inocente, cômico e sério, útil e inútil, banal e complexo, pois é assim que pode aprender a enfrentar diferentes situações. Precisamos de narrativas que nos situem no tecido das vozes e permitam significar nossa singularidade, pois nutrem a imaginação e promovem familiaridade com a língua, com suas possibilidades, com os ditos e não-ditos que emergem dos textos. É da infância enfrentar o desconhecido e o aberto em suas experiências de ler o mundo.

Falar de infância é fazer referência à experiência de começar-se no mundo. A experiência de começar a ler é radical ao implicar a potência vital de jogar com o dizível e o indizível, com o real e

\footnotetext{
5 “As aventuras de Pinóquio", originalmente escrito em capítulos, numa série publicada no jornal infantil italiano de Ferdinando Martini, Giornale per i Bambini, entre julho de 1881 e janeiro de 1883, foi publicada em livro pela Felice Paggi - Libraio Editore, com ilustrações de Enrico Mazzanti, em 1883.
} 
o ficcional. A complexidade de começar a estabelecer relações ao "aprender a vincular o lúdico com a lucidez" (BÁRCENA, 2004, p. 122) emerge como uma potente definição de infância. Definição que supõe disponibilidade para conceber a Educação Infantil como tempo e lugar de aprender a encantar-se com o ato lúdico de alternadamente pensar e sonhar, idear e devanear, aprender a magicar e a imaginar.

A imaginação, âmbito entrelaçado entre os sentidos e a razão, no qual convergem todas as possibilidades de viver uma experiência leitora, ainda que este leitor, muitas vezes, não reconheça as letras, é um leitor que vive a experiência da leitura, graças a existência de outro que o aproxima através da escuta da palavra escrita. O texto literário, destaca Gadamer (2009), não cumpre apenas função comunicativa pela exigência de estar presente em sua manifestação de linguagem.

\footnotetext{
Não basta lê-lo, é preciso ouvi-lo, mesmo que só com o ouvido interior. É só assim que a palavra adquire sua autopresença no texto literário. Não se limita a tornar presente o que é dito, mas se apresenta a si mesma em sua realidade sonora (GADAMER, 2009, p. 407).
}

Um leitor que desde a mais tenra idade e desde a sua ingenuidade até suas perversidades, se permite maravilhar na escuta das imagens poéticas que emergem das narrativas. Para este leitor, esta imagem pode ser o germe de um mundo, o germe de um universo imaginado diante do devaneio de um poeta (BACHELARD, 2009). Um encantamento que exige arriscar-se na imagem e na palavra para aprender o esforço de um pensamento em ato que não exclui a diversão e a alegria de participar do mundo.

Participar do mundo demanda tanto esforço laborioso quanto tempos lentos. A experiência da lentidão é o tempo dos excessos (BACHELARD, 1991), portanto, o tempo das crianças "não é linear para elas mesmas. Os gregos o chamaram Aion. A intensidade dessa vida, em todas e cada uma de suas condições divergentes, não entra em um relato fundado no utilitarismo das ações efetivamente realizadas" (SKLIAR, 2012, p. 17). Porém, muitas vezes a experiência de ler é ofertada às crianças pequenas atrelada a um desejo adulto de ir mais rápido, como uma necessidade imediata de responder algumas perguntas ou completar algumas tarefas. Mas que experiência é essa promovida a partir da pressa e do medo em não corresponder à resposta esperada? O que essa experiência tem mostrado além da necessidade de seguir um caminho fácil e seguro?

Quer seja na época de Collodi, com os textos que os alunos repetem como papagaios, quer na nossa, com grande quantidade de informação, é bastante fácil ser superficialmente letrado, seguir 
uma comédia televisiva, entender a mensagem de um anúncio publicitário, ler um slogan ou usar um computador. Mas para chegar mais longe e de uma forma mais profunda, para ter a coragem de enfrentar medos, dúvidas e segredos ocultos, para questionar o funcionamento da sociedade, necessitamos de aprender a ler de outra maneira, de forma diferente, que nos permita aprender a pensar. Talvez Pinóquio se converta num rapaz no final das suas aventuras, mas a verdade é que continuará a pensar como um boneco. (MANGUEL, 2003, p. 27)

A experiência de leitura nasce da relação entre silêncio e escuta, dessas vozes que chegam do texto, da voz de quem lê para a criança; das vozes que falam com esta criança, vozes distantes do vocabulário coloquial, da pressa e da simples transmissão de informação. Este é o momento em que outras possibilidades no campo da literatura se abrem. Porém, se é graças à escola que muitos se aproximam da leitura literária, essa experiência só pode ser vivida por cada um de forma diferente. Ainda que as crianças vivenciem a literatura de maneira semelhante, a vivem de diferentes modos ao tornarem própria uma experiência de compreensão de si no mundo. Aqui, "a linguagem adquire sentido para a criança quando constitui situação para ela" (MERLEAU-PONTY, 1999, p. 537). Isto é, quando a situa no mundo e a orienta em dada situação na qual a palavra é apanhada e assumida pela experiência pré-reflexiva do corpo, esse "sensível exemplar" que ao sentir se sente e nos une sensorialmente às coisas antes de significações intelectuais porque é nele que a existência se realiza (MERLEAU-PONTY, 1999). Destacar o pensamento encarnado no corpo - em situação - implica acolher que, para as crianças,

\footnotetext{
a "história" e o expresso não são "ideias" ou "significações", a fala e a leitura não são "operações intelectuais". A história é um mundo que se deve poder fazer aparecer magicamente, pondo óculos e debruçando-se sobre um livro. A potência que a linguagem tem de fazer existir o expresso, de abrir caminhos, novas dimensões, novas paisagens para o pensamento é, em última análise, tão obscura para o adulto quanto para a criança (MERLEAU-PONTY, 1999, p. 538).
}

O sentido, aqui, se expõe à criança "magicamente durante a encantação linguística, assim como a história saía do livro da avó" (MERLEAU-PONTY, 1999, p. 538). Porém, a leitura no contexto escolar costuma ser fortemente atrelada a um senso de obrigação. Lê-se para dar respostas, lê-se para interpretar um texto, lê-se sob a condição de comprovar o que foi lido. De modo recorrente, a escola reclama a falta de "estímulo" às práticas de leitura literária e opta por reforçar a ideia de "leitura para" ensinar algo em detrimento do encantamento linguístico. Opção escolar redutora da experiência literária ao negar o encontro com o prazer estésico da experiência de linguagem como 
modulação da existência. O "ensino da literatura", intimamente ligado ao imaginário escolar adulto, desconsidera a impossibilidade de determinar o acontecimento da leitura, pois como fenômeno em situação "não tem garantias contra o desgaste do tempo (a gente se esquece e esquece), ela não conserva ou conserva mal a sua posse, e cada um dos lugares por ela passa é repetição do paraíso perdido" (CERTEAU, 1994, p. 270). O encontro com a literatura, por apresentar um acontecimento inter-humano é sempre o encontro com um acontecimento inacabado, não pode ser ensinado, previamente determinado, apenas vivido, sentido, partilhado.

A formação de um leitor não se dá meramente pela execução de ações relacionadas ao tema da leitura ou à leitura da palavra. Consideramos relevante perceber quão longa é a distância entre o primeiro encontro com o livro, seja pelas narrativas partilhadas em família ou pela voz de um professor na Educação Infantil, e a efetivação da autonomia do leitor. Muitos anos separam os rabiscos nos livros infantis das frases sublinhadas em livros de literatura. Há uma distância imensa entre as vozes familiares que nos ninam com contos de fadas e aqueles trechos inesquecíveis que somos capazes de repetir sem errar uma vírgula. A paixão não é ensinada, ela é encarnada.

Sabemos que não existe leitor da palavra sem a existência de livros, por isso a necessidade de garantir acesso à literatura, na escola, em bibliotecas, mas não podemos esquecer a importância do encontro com outro leitor, um leitor que deflagre curiosidade, afeto e fomente o diálogo neste novo leitor. Aí se evidencia a presença insubstituível de um professor-leitor, que jamais será capaz de ensinar às crianças o seu gosto literário ou a sua experiência com a leitura, mas que poderá transmitir seu repertório literário e contribuir para que essas crianças constituam o seu próprio repertório literário na busca de seus afetos narrativos.

As coisas que a literatura pode buscar e ensinar são poucas, mas insubstituíveis: a maneira de olhar o próximo e a si próprios, de relacionar atos pessoais e fatos gerais, de atribuir valor a pequenas coisas ou a grandes, de considerar os próprios limites e vícios e os dos outros, de encontrar as proporções da vida e o lugar do amor nela, e sua força e seu ritmo, e o lugar da morte, o modo de pensar ou de não pensar nela; a literatura pode ensinar a dureza, a piedade, a tristeza, a ironia, o humor e muitas outras coisas assim necessárias e difíceis. O resto, que se vá aprender em algum outro lugar, da ciência, da história, da vida como nós todos temos de ir aprender continuamente. (CALVINO, 2009a, p.21)

Ao serem provocadas a descreverem suas leituras de escola, as crianças demonstraram grande preocupação com o futuro. Ao narrarem a sua experiência de aluno, foi recorrente a ideia de ser necessário, a cada ano que passa, desvencilhar-se da meninice e dedicar-se cada vez mais à escola. 
Há uma grande preocupação com trabalhos e provas, além de um enorme senso de responsabilidade e vontade de sair-se bem, de ser o primeiro. A escola, para as crianças, é um meio para chegarem a um fim mais justo e melhor. Ou seja, para as crianças a disciplina escolar é justificável. Elas reclamam das filas, mas acreditam que sejam necessárias, gostariam de permanecer na sala no recreio, só que esta é chaveada e eles prontamente explicam que a sala é chaveada para não fazerem bagunça. Skliar (2003) traça uma síntese eficaz da passagem de meninos para alunos: "esperar que se deteriore, que se torne adulto. Fazer com que se ponha ao nosso alcance. Explicá-lo. Domesticá-lo para desenhá-lo, para traçar seu contorno, para dar a entender seu conteúdo”.

Ainda que suas narrativas falem de filas, normas, regras, obrigações, atividades repetitivas e cansativas dadas pela simplificação nas quais são apresentadas, estas emergem como necessário rito de passagem para a vida adulta. A instituição escolar como a única garantia de um trabalho ou como a única fonte de conhecimento - essa fala é muito viva nos discursos das crianças, parece que hoje, um século depois da invenção de Pinóquio, as crianças ainda necessitam da escola para convertê-las em "homens de bem", aqueles que podem ostentar o status de bem educados e, mais do que isso, bem empregados.

Processos acelerados de escolarização não apenas retiram a criança do seu mundo, convertendo-a em um Visconde Partido ao Meio, que assim como no conto de Ítalo Calvino (2009b), não pode ser um só, mas interrompem seus tempos. Porém, "ler é não ser interrompido" escreve Skliar (2012, p. 21). Antes da escola, o menino é aquele que não sabe, que ainda não está completo, durante a escola ele encontra-se em preparação, domesticado, convertido em aluno e "menino de bem".

O contrário da meninice é isso que poderíamos nomear como "uma estância sem gestos". O adulto sabe como confinar a meninice, como derrotá-la. E talvez essa estância sem gestos seja uma das metáforas do educar. Uma das mais frequentes. Uma das menos interessantes. Uma das que mais ferem. (SKLIAR, 2012, p. 19)

Ao compartilharem a sua leitura de escola, principalmente ao narrarem sua experiência de aluno, é possível constatar a ideia das crianças de que a medida que os anos passam é necessário desvencilhar-se da meninice e dedicar-se cada vez mais aos estudos. Como se os estudos e a infância, as regras e a brincadeira, o silêncio e a inquietude, não pudessem caminhar juntos. Em muitos relatos falam do dia da semana reservado à biblioteca. Neste dia as crianças escolhem livros que devem ser lidos somente em casa, pois na escola elas só podem ler o que for escolhido pela professora. A biblioteca é narrada como um local de silêncio e disciplina: não se pode correr, não se pode conversar, 
os livros devem ser manuseados com cuidado, todos devem permanecer sentados. O que as crianças dizem é o que Bachelard (2004, p. 97) denuncia com veemência ao afirmar que "simplificar é sacrificar" (2004, p.97).

\title{
INFÂNCIA E LEITURA: O QUE PODEM AS PALAVRAS?
}

\begin{abstract}
As relações não são mais do que uma extensão da palavra, é a Palavra que é "a morada", é implantada como uma origem na prosódia das funções, ouvidas, mas ausentes. Aqui as relações fascinam, é a Palavra que alimenta e cumula como o desvendamento súbito de uma verdade; dizer que essa verdade é de ordem poética é apenas dizer que a Palavra poética nunca pode ser falsa porque ela é total; brilha com uma liberdade infinita e se propõe a irradiar em direção a mil relações incertas e possíveis. ROLAND BARTHES (Grau zero da escrita)
\end{abstract}

Na sociedade de Collodi, a escola é a grande responsável por transformar meninos comuns em meninos de bem. É na escola que se aprende uma profissão, é ela que ensina cálculos, leitura e escrita e é também ela que mostra a importância de obedecer e adaptar-se às regras de convivência. Pinóquio, porém, compreende muito cedo que a leitura seria o passaporte para tornar-se um menino de verdade. Ao longo de suas aventuras, a importância da leitura lhe é mostrada inúmeras vezes, seja pelo Grilo que o chama de ignorante por não conhecer as palavras, seja pela impossibilidade de compreender as informações em um cartaz na praça ou pelas inúmeras vezes que o chamaram de burro por não interpretar os códigos escritos.

Ler, portanto, seria o primeiro passo para converter-se em um cidadão, ou, nas palavras de Collodi (2011), em um menino de verdade. Mas o que significa ler? Manguel (2007) destaca que se muitos dizem que ler significa decodificar símbolos escritos, podemos, todavia, ir um pouco além, e entender que ler é mais que decodificar e sim compreender o sentido das palavras ou, ainda, chegarmos ao ideal da leitura que é a capacidade de interpretação do texto, ou seja, quando nos apropriamos do sentido. Para Manguel (2007), essa terceira aprendizagem, é a mais difícil, a mais perigosa e a mais poderosa, e a que Pinóquio nunca chega a cumprir. As tentações da vida, as piadas de seus companheiros, a relação fria e distante com seu pai, fizeram com que o boneco jamais se convertesse em um leitor. Ser leitor não é ser capaz de falar as palavras que lê mas de ler

todas que se escondem no livro, já que cada palavra foi escrita num certo ponto para esconder outras, incontáveis palavras. Procurará palavras clandestinas - a rigor, todas as palavras de um livro são clandestinas -, não para torná-las mercadorias públicas, mas porque são palavras que contrabandeiam outras palavras, são travestidas, e seu travestimento, como tal, tem todos os 
incontáveis significados que só podem ser identificados num travestimento (MANGANELLI, 2002, p. 15).

Esse travestimento, essa potência do não dito no dito, permanece estranha ao agora menino, fazendo de sua saga de Visconde Partido ao Meio uma forte presença. Enquanto boneco que falava, brincava e comia, Pinóquio jamais chegou a ser um brinquedo de verdade, pois como menino teve interrompida sua potência de infância: começar-se.

Educar é um processo lento e difícil. Para Manguel (2007, p. 27) trata-se de "dois adjetivos que na nossa época se converteram em defeitos em vez de elogios. Hoje em dia, parece quase impossível reconhecer os méritos da lentidão e do esforço deliberado". Vigora a simplificação da produtividade dos aceleramentos. Porém, com Bárcena (2012), consideramos que ler acontece desde muito pequenos.

As narrativas chegam muito cedo à vida das crianças. Com alguns dias ela chega ao bebê na forma de canções de ninar ou através de canções como "o cravo brigou com a rosa" ou "sapo cururu", que nada mais são que histórias musicadas. Como afirma Gadamer (2004, p. 23), a musicalidade da língua significa aqui “a completa concatenação interior de som e significado, de sentido e ser da palavra. Esta musicalidade representa o ápice absoluto das possibilidades da palavra poética, que mantém sempre diferentes maneiras de equilíbrio entre o som e o significado". Ao ser embalada no colo dos familiares, normalmente as músicas que os acompanham são as músicas que estes ouviam quando criança, assim como as histórias, sejam contos de fada, histórias inventadas ou as memórias de suas famílias. As narrativas estão presentes nos conselhos dos avós ou nas façanhas de invencibilidade contadas pelos irmãos mais velhos.

Se deixamos de ler com e para as crianças, se deixamos de narrar e cantar, de contar-lhes histórias, se abandonamos definitivamente o propósito de lhes apresentar o mundo, os enterramos em vida, os emparedamos. Eis o poder da palavra: uma vida sem a palavra, seja ela escrita ou falada, é uma vida sem imaginação, sem referências para compreender e compreender-se no mundo comum. Sem a potência de habitar a linguagem para produzir efeitos de realidade, para alternadamente pensar e sonhar.

A literatura, por ser arte, diz respeito ao fingere 6 , ao "fazer de conta" para forjar realidades, para fazer ser o que não é e suspender temporalidades. Por isso, Manganelli (2002, p. 48) pode afirmar

\footnotetext{
${ }^{6}$ Fingere vem do verbo latino fingo [is, ere, finxi, fictum]: modelar em barro; modelar em qualquer substancia plástica, formar, representar, esculpir; imaginar, inventar, fingir; ficção. (Conforme Dicionário de Latim-Português, Porto Editora). Fingere remete à ficção e ao fingir e fingir ao fazer.
} 
que "Pinóchio não mente, quem mente é a linguagem". Aqui, imaginar é jogar com a realidade e com possibilidades de realidade. Nesse sentido, real e ficcional emergem profundamente vinculados no ato de tornar inteligível o que nos acontece na coexistência. O mais impossível dos mundos só nos impressiona, perturba ou comove se tomamos como referência nossas experiências e conhecimentos do mundo real ${ }^{7}$. E as crianças, destaca Fink (1966, p.65), “já enfrentam distinções que colocam ao pensamento uma problemática das mais difíceis" quando em seus jogos são convocadas a enfrentarem as ambiguidades entre o tangível e o imaginário como modo de instaurar sentidos com outros na convivência. Desde muito pequenas, podem fingir porque jogam um jogo através do qual podem formular sentido - dar existência - à infinidade de coisas que aconteceram, estão acontecendo ou vão acontecer no mundo real.

A palavra como produção artística, particularmente na aprendizagem da literatura, oral ou escrita, de modo geral é negligenciada nos projetos escolares. A literatura, sempre considerada na área do ensino de língua portuguesa, dificilmente aparece ao lado das artes plásticas, do teatro, da música, da dança. Porém, todas - cada uma na invenção ou intensificação de suas diferenças (NANCY, 2006) - exigem o ato de instaurar sentidos. Nessa compreensão, o ato da leitura é ato comum à ciência (leitura do real) e à poética (devaneios da leitura), pois tanto a objetividade racional quanto a ambiguidade da imaginação poética, tanto a reflexão quanto o devaneio poético, exigem o ato lúdico de ler - exigem a potência de interpretar como modo de estabelecer diálogos.

Porém, constata Skliar (2011, p. 27), em educação a conversação é cada vez mais difícil, “quase não se conversa com outros, quase não se conversa de outras coisas; no melhor dos casos apenas se conversa sempre entre os mesmos e sempre das mesmas coisas". Essa dificuldade para a escuta de outras vozes nega a experiência de conversar como experiência de estar em linguagem. Experiência que pressupõe a convivência, a abertura ao outro e a outros, pela disponibilidade de escuta e interlocução com suas histórias e narrativas. Conversar supõe orquestrar a pluralidade de gestos do corpo, modos de olhar e de escutar, de falar e de pensar. Todavia, nunca falamos tanto de nós mesmos, nunca estivemos tão pouco dispostos a ouvir, a esperar, a emprestar nosso tempo para nos relacionarmos, pelo pensamento, com o mundo.

Talvez, a rapidez da contemporaneidade tenha nos convertido em exímios discursadores de nós mesmos ao esquecermos que conversar é afetar-se, é deixar-se tocar pelo outro, é estar em dissonância e tolerar o fato de que nosso interlocutor, muitas vezes, pensa e sente o mundo diferente

\footnotetext{
7 Aqui, denominamos de mundo real o mundo de nossa experiência, sem nos determos em conceituações ou compromissos ontológicos.
} 
de nós. Mais do que isso, conversar, muitas vezes, é se deixar romper, se modificar e até machucar. A troca, o ato de deixar-se se afetar, sempre infere algum tipo de risco. Não será essa a grande dificuldade de estar em diálogo?

Conversas difíceis, conversas especiais, conversas que nos lavam a alma, conversas que nos expõem e nos ensinam a nós mesmos, conversas sobre a vida, conversas sobre o outro, conversas sobre banalidades, conversas que nos devastam. Talvez nada nos torne mais presentes no mundo que o gesto de conversar, de compartilhar dúvidas e saberes, de intercambiar experiências ou, simplesmente, de trocar sensações. Conversar para ler o outro, para ler o que há de clandestino em suas palavras, para ler o não dito e também o indizível.

A leitura de palavras - ou de livros - é apenas um dos muitos modos de ler. Como destaca Manguel (1997, p. 20), ler "vem antes de escrever. Uma sociedade pode existir - existem muitas, de fato - sem escrever, mas nenhuma sociedade pode existir sem ler”. Ler é uma função comum, todos lemos a nós e ao mundo à nossa volta. Diz respeito, desde o nascimento, à dimensão existencial do humano. Lemos para decifrar e traduzir significados, para nos situar no mundo, para vislumbrar o que somos e onde estamos. Lemos para conversar sobre a coexistência no mundo comum. Talvez tenhamos que reaprender a conversar.

\section{REFERÊNCIAS}

BACHELARD, Gaston. A terra e os devaneios da vontade. São Paulo: Martins Fontes, 1991.

BACHELARD, Gaston. A poética do devaneio. Martins Fontes, 1988.

BACHELARD, Gaston. Ensaio sobre o conhecimento aproximado. Tradução Estela dos Santos Abreu. Rio de Janeiro: Contraponto, 2004.

BÁRCENA, Fernando. El alma del lector - la educación como gesto literário. Bogotá: Babel Livros, 2012.

BÁRCENA, Fernando. El delírio de las palabras. Ensayo para una poética del comienzo. Barcelona: Herder Editorial, 2004.

BARTHES, Roland. O Grau zero da escrita. $2^{\text {a }}$ ed. São Paulo: Martins Fonte, 2004.

BRASIL. Lei $\mathbf{n}^{\mathbf{0}}$.9.394, de 20 de dezembro de 1996. Estabelece as diretrizes e bases da educação nacional. Diário Oficial [da] República Federativa do Brasil, Brasília, DF, 23 dez. 1996.

BRASIL. Lei $\mathbf{n}^{\mathbf{0}} \mathbf{. 1 1 . 2 7 4}$, de 6 de fevereiro de 2006. Altera a redação dos arts. 29, 30, 32 e 87 da Lei nº 9.394 de 20 de dezembro de 1996, dispondo sobre a duração de 9 (nove) anos para o ensino fundamental, com matrícula obrigatória a partir dos 6 (seis) anos de idade.

BRASIL. Ministério da Educação. Ministério da Educação. Conselho Nacional de Educação. Resolução CEB n. 05, 17 dez. 2009. Institui as Diretrizes Curriculares Nacionais para a Educação Infantil. Diário Oficial República Federativa do Brasil, Brasília, DF, 18 dez. 2009. Seção 1, p. 18.

BRASIL. Lei no 12.796, de 4 de abril de 2013. Altera a Lei n. 9.394, de 20 de dezembro de 1996. Diário Oficial [da República Federativa do Brasil], Brasília, DF, 04 abr. 2013. 
CALVINO, Ítalo. O miolo do leão. Assunto encerrado: discursos sobre literatura e sociedade. São Paulo: Companhia das Letras, 2009a.

CALVINO, Ítalo. O visconde partido ao meio. São Paulo: Companhia das Letras, 2009b.

CERTEAU, Michel de. A invenção do cotidiano: 1. artes de fazer. Tradução de Ephraim Ferreira Alves. Nova edição, estabelecida e apresentada por Luce Giard. Petrópolis, RJ: Vozes, 1994.

COLLODI, Carlo. As aventuras de Pinóquio. São Paulo: Cosac Naify, 2011.

FINK, Eugen. Le jeu comme symbole du monde. Traduit par Hans Hildenberg et Alex Lindenberg. Paris: Minuit, 1966.

GADAMER, Hans-Georg. Poema y diálogo. Traducción: Daniel Najmías y Juan Navarro. Barcelona: Gedisa, 2004.

GADAMER, Hans-Georg. Verdade e Método II: complementos e índice. Petrópolis, RJ: Vzes, 2009.

MANGANELLI, Giorgio. Pinóquio: um livro paralelo. São Paulo: Companhia das Letras, 2002.

MANGUEL, Alberto. Uma história da leitura. São Paulo: Companhia das Letras, 1997.

MANGUEL, Alberto. Cómo Pinocho aprendió a ler. Dezembro 2003. Disponível em: <http://www.letraslibres.com/revista/convivio/como-pinocho-aprendio-leer > Acesso em 12 de junho 2017.

MERLEAU-PONTY, Maurice. Fenomenologia da percepção. Tradução de Carlos Alberto Ribeiro de Moura. São Paulo: Martins Fontes, 2011.

NANCY, Jean-Luc. La imagen: Mímesis \& Méthexis. Universidad Complutense, Madrid, Escritura e imagen, Vol. 2, p. 7-22, 2006.

NARODOWSKY, Mariano. Infância e Poder: conformação da pedagogia moderna. Bragança Paulista: Editora da Universidade de São Francisco, 2001.

RANCIÈRE, Jacques. A partilha do sensível: estética e política. Tradução Mônica Costa Netto. Sao Paulo: EXO experimental org.;Ed. 34, 2005.

SKLIAR, Carlos. Pedagogia (improvável) da diferença: e se o outro não estivesse aí? Rio de Janeiro. DP\&A, 2003.

SKLIAR, Carlos. As interrupções no corpo, a atenção, a ficção e a linguagem da infância. In: XAVIER, Ingrid Müller; KOHAN, Walter Omar. Filosofar: aprender e ensinar. Belo Horizonte: Autêntica Editora, 2012.

SKLIAR, Carlos. Conversar e Conviver com os Desconhecidos... In: FONTOURA, Helena Amaral da (Org.). Políticas Públicas, Movimentos Sociais: desafios à pós-graduação em educação em suas múltiplas dimensões. Rio de Janeiro: Anped Nacional, Coleção Anped Sudeste. 2011. Livro 3. p.27-37. Disponível em: <http://www.fe.ufrj.br/anpedinha2011/ebook3.pdf>. Acesso em: 22 jun.2017. 


\section{PINÓQUIO, LEITURA E ESCOLARIZAÇÃO DAS CRIANÇAS PEQUENAS: COMO TRANSFORMAM-SE EM BONECOS}

Resumo

Diante do desafio contemporâneo da entrada de bebês e crianças pequenas na Educação Básica, o artigo aproxima educação, literatura e infância para problematizar a experiência de leitura nos processos iniciais de escolarização. A escuta das narrativas de crianças de duas escolas estaduais (RS) em torno da imagem do bom aluno apresenta semelhanças com "As Aventuras de Pinóquio", o qual se converte em um bom menino mas pensa como um boneco. A interlocução entre a obra "Pinóquio: um livro paralelo", a fenomenologia de Bachelard e a hermenêutica de Gadamer sustenta a ideia de linguagem como experiência existencial de mundo, na qual o sentido emerge em situação para o leitor. A alteridade nos modos de ler e interpretar o mundo permite afirmar que ler é mais, e outra coisa, que alfabetizar.

Palavras-chave: Linguagem e infância - Experiência de leitura - Escolarização

\section{PINOCCHIO, READING AND SMALL CHILDREN'S SCHOOLING: HOW THEY TURN INTO PUPPETS}

Abstract

Understanding the entry of babies and small children into Primary Education as a contemporary challenge, this work aims at bringing together education, literature and childhood in order to discuss the experience of reading in the early stages of schooling. Children from two State Schools (RS) show through their narratives the image they have of a good student, and such narratives resemble "The Adventures of Pinocchio", novel in which a wooden puppet turns into a boy but still thinks as a puppet. The dialogue between "Pinocchio: a parallel book", Bachelard's phenomenology and Gadamer's hermeneutics sustain the idea of language as an existential experience of the world, in which a meaning emerges from the situation readers find themselves. Alterity in the ways of reading and interpreting the world make it possible to conclude that reading is more, and another thing, something different from just providing literacy instruction.

Keywords: Language and childhood - Experience of reading - Schooling

\section{PINOCHO, LECTURA Y ESCOLARIZACIÓN DE LOS NIÑOS PEQUEÑOS: COMO SE VUELVEN EN MUÑECOS}

Resumen

Delante el desafío contemporáneo de la entrada de bebés y niños pequeños en la Educación Básica, el artículo aproxima educación, literatura e infancia para problematizar la práctica de lectura en los procesos iniciales de escolarización. La escucha de las narrativas de niños de dos escuelas estaduales (RS) en vuelta de la imagen del bueno alumno presenta semejanzas con "Las Aventuras de Pinocho", el cual se vuelve en un bueno chico, pero piensa como un muñeco. La interlocución entre la obra "Pinocho": un libro paralelo", la fenomenología de Bachelard y la Hermenéutica de Gadamer sostiene la idea de lenguaje como experiencia existencial de mundo, en la cual el sentido emerge en situación para el lector. La alteridad en las maneras de leer e interpretar el mundo permite afirmar que leer es más, es otra cosa, que alfabetizar.

Palabras clave: Lenguaje e infancia- Práctica de lectura- Escolarización 